\title{
Octahedral PtNi nanoparticles with controlled surface structure and composition for oxygen reduction reaction
}

\author{
Yizhong Lu ${ }^{1,2}$, Larissa Thia ${ }^{1}$, Adrian Fisher ${ }^{3}$, Chi-Young Jung ${ }^{4}$, Sung Chul Yi ${ }^{5^{*}}$ and Xin Wang ${ }^{1 *}$
}

\begin{abstract}
Controlling the surface structure and composition at the atomic level is an effective way to tune the catalytic properties of bimetallic catalysts. Herein, we demonstrate a generalized strategy to synthesize highly monodisperse, surfactant-free octahedral $\mathrm{Pt}_{x} \mathrm{Ni}_{1-x}$ nanoparticles with tunable surface structure and composition. With increasing the Ni content in the bulk composition, the degree of concaveness of the octahedral $\mathrm{Pt}_{x} \mathrm{Ni}_{1-x}$ nanoparticles increases. We systematically studied the correlation between their surface structure/composition and their observed oxygen reduction activity. Electrochemical studies have shown that all the octahedral $\mathrm{Pt}_{x} \mathrm{Ni}_{1-x}$ nanoparticles exhibit enhanced oxygen reduction activity relative to the state-of-the-art commercial $\mathrm{Pt} / \mathrm{C}$ catalyst. More importantly, we find that the surface structure and composition of the octahedral $\mathrm{Pt}_{x} \mathrm{Ni}_{1-x}$ nanoparticles have significant effect on their oxygen reduction activity. Among the studied $\mathrm{Pt}_{x} \mathrm{Ni}_{1-x}$ nanoparticles, the octahedral $\mathrm{Pt}_{1} \mathrm{Ni}_{1}$ nanoparticles with slight concaveness in its (111) facet show the highest activity. At $0.90 \mathrm{~V}$ vs. RHE, the Pt mass and specific activity of the octahedral $\mathrm{Pt}_{1} \mathrm{Ni}_{1}$ nanoparticles are 7.0 and 7.5-fold higher than that of commercial $\mathrm{Pt} / \mathrm{C}$ catalyst, respectively. The present work not only provides a generalized strategy to synthesize highly monodisperse, surfactant-free octahedral $\mathrm{Pt}_{x} \mathrm{Ni}_{1-x}$ nanoparticles with tunable surface structure and composition, but also provides insights to the structure-activity correlation.
\end{abstract}

Keywords: PtNi, octahedral, concave, surface structure, oxygen reduction reaction

\section{INTRODUCTION}

Since the study of single-crystals $\mathrm{Pt}_{3} \mathrm{Ni}(111)$ published in
2007 [1], in which a 10 times higher specific activity than the corresponding $\mathrm{Pt}(111)$ and 90-fold improvement over the commercial $\mathrm{Pt} / \mathrm{C}$ catalyst was observed, octahedral PtNi nanocrystals have drawn significant interest in recent years for the oxygen reduction reaction (ORR). In the past years, a number of research groups have successfully prepared octahedral PtNi alloys nanoparticles enclosed by well-defined (111) facets [2-4]. Most synthetic methods were adopted to obtain these well-faceted octahedral PtNi nanoparticles with tunable size, composition, and structure by using strongly adsorbing capping agents $[3,4]$. However, the presence of these capping agents on the surface of these PtNi nanocrystals not only greatly limits the free access of surface active sites, but also hinders the well understanding of the correlation between the observed catalytic activity and their inherent structure of PtNi nanoparticles [5]. To this end, Carpenter et al. [6] from the General Motors R\&D Center of the United States demonstrated a simple solverthermal technique to obtain surfactant-free PtNi octahedron enclosed by eight (111) facets by using $N, N$-dimethylformamide (DMF) as a complexing agent, solvent, and reducing agent. Since then, this simple method was extensively adopted to synthesize surfactant-free octahedral PtNi nanoparticles $[5,7,8]$. Importantly, due to the free accessibility of active sites on the surface, the as-synthesized well-defined, surfactant-free octahedral PtNi nanoparticles exhibited enhanced ORR activity and durability [8]. Nevertheless, due to the absence of any capping agents, the as-prepared

\footnotetext{
${ }^{1}$ School of Chemical and Biomedical Engineering, Nanyang Technological University, Singapore 639798, Singapore

${ }^{2}$ Cambridge Centre of Advanced Research in Energy Efficiency in Singapore (CARES), Singapore 138602, Singapore

${ }^{3}$ Department of Chemical Engineering and Biotechnology, University of Cambridge, New Museums Site, Pembroke Street, Cambridge, CB2 3RA (UK).

${ }^{4}$ Hydrogen and Fuel center, Korea Institute of Energy Research (KIER), 20-41, Sinjaesaengeneogi-ro, Haseo-myeon, Jellabuk-do 56332, Republic of Korea

${ }^{5}$ Department of Chemical Engineering, Hanyang University, Haengdang-dong, Seongdong-gu, Seoul 133-791, Republic of Korea

* Corresponding authors (emails: WangXin@ntu.edu.sg (Wang X); scyi@hanyang.ac.kr (Yi SC))
} 
PtNi nanoparticles suffer from obvious agglomeration and thus the intrinsic catalytic activity of nanoparticles could not be fully realized. Moreover, the octahedral shape of the surfactant-free PtNi nanoparticles are not well-defined which is also normally accompanied with other shaped nanoparticles. Recent experimental and theoretical studies have shown that $\mathrm{Pt}$ atoms located at edges and/or corners of octahedral nanoparticles are inactive for ORR due to the low-coordinated edge and the corner sites are blocked strongly by adsorbed hydroxyl groups and oxygen atoms formed during the operation of the polymer electrolyte fuel cells (PEMFCs) $[9,10]$. In contrast, Pt atoms at the (111) facet are active. In addition, the Pt atoms at edges and/or corners are easier to dissolve into electrolytes than those at facets, thus resulting in low durability of catalysts [10]. Thus, the design and synthesis of highly monodisperse, surfactant-free octahedral PtNi nanoparticles with (111) surface are desirable but still remain a significant challenge [3].

Generally, the catalytic performance of nanocrystals can be finely and effectively manipulated by changing their surface structure and composition, which mediate the electronic structure, surface atomic arrangement, and coordination $[1,11-14]$. For instance, the $\mathrm{Pt}_{3} \mathrm{Ni}(111)$ crystal surface reported by Stamenkovic has an unusual electronic structure (d-band center positon) and arrangement of surface atoms in the near-surface region, where the outermost layer contains almost $100 \% \mathrm{Pt}$, the third layer is Pt-rich, and the Ni-rich is subsurface layer $[1,15]$. The weak interaction between the Pt surface atoms and nonreactive oxygenated species increases the number of active sites for $\mathrm{O}_{2}$ adsorption and thus the enhanced oxygen reduction activity [15]. Zhang et al. [4], reported the synthesis of monodisperse $\mathrm{Pt}_{3} \mathrm{Ni}$ nanoctahedra and nanocubes via a high temperature organic solution chemistry approach and found that the ORR activity of (111)-facet-terminated nanoctahedra were significantly more active than the (100)-bounded nanocubes in $0.1 \mathrm{~mol} \mathrm{~L}^{-1} \mathrm{HClO}_{4}$ solution. The mass and specific activity of nanoctahedra are 4 and 7 times, respectively, higher than those of $\mathrm{Pt} / \mathrm{C}$. Xia and co-workers [3] successfully synthesized PtNi octahedra of $9 \mathrm{~nm}$ in size with well-defined (111) facets on their surface and observed a specific activity 51-fold higher than that of the commercial Pt/C catalysts for the ORR at $0.93 \mathrm{~V}$, and a record high mass activity of $3.3 \mathrm{Amg}_{\mathrm{Pt}}^{-1}$ at 0.9 V. Peter Strasser and co-workers [8] demonstrated that compositional segregation in concave octahedral $\mathrm{Pt}_{x} \mathrm{Ni}_{1-x}$ nanoparticles correlated with their surface electrocatalytic ORR activity. They found that the initial $\mathrm{Pt}_{x} \mathrm{Ni}_{1-x}$ octahedra featured a Pt-rich frame along their edges and corners, and their $\mathrm{Ni}$ atoms were preferentially segregated in their (111) facets. The dealloyed activated $\mathrm{Pt}_{x} \mathrm{Ni}_{1-x}$ octahedra showed the ORR improvenment was 6-10 times and 10-15 times in mass and specific activities compared with the commercial $\mathrm{Pt} / \mathrm{C}$ catalysts, respectively. More recently, Huang et al. [2], showed that molybdenum (Mo) doped $\mathrm{Pt}_{3} \mathrm{Ni}$ octahedra exhibited a specific activity of $10.3 \mathrm{~mA}$ $\mathrm{cm}^{-2}$ and mass activity of $6.98 \mathrm{~A} \mathrm{mg}_{\mathrm{Pt}}^{-1}$, which are 81 - and 73-fold enhancements relative to the commercial $\mathrm{Pt} / \mathrm{C}$ catalysts, respectively. Theoretical calculations suggest that Mo prefers surface vertex/edges sites in oxidizing conditions and hence enhances the ORR performance. Thus, by engineering the surface structure and composition of octahedral PtNi nanoparticles, we could effectively tune the electronic band structure towards a more favourable adsorption and thus improve their ORR catalytic activity and durability.

Herein, for the first time, we report a facile one-pot solvothermal strategy to synthesize highly monodisperse, surfactant-free octahedral $\mathrm{PtNi}$ nanoparticles without using any bulky and strongly adsorbing capping agents. By controlling the initial ratios of Pt and Ni precursors, highly monodisperse octahedral PtNi nanoparticles with similar size but different compositions were obtained. Interestingly, we found that the degree of concaveness in their (111) facets of octahedral PtNi nanoparticles increased with the initial Ni content in the bulk composition. With reproducible control of size, we were able to study the effect of nanoparticle surface structure and composition on their ORR activity. Due to the surface exposure of active sites, the as-synthesized octahedral $\mathrm{Pt}_{x} \mathrm{Ni}_{1-x}$ nanoparticles exhibited enhanced ORR activity. Among the studied octahedral $\mathrm{Pt}_{x} \mathrm{Ni}_{1-x}$ nanoparticles, the octahedral $\mathrm{Pt}_{1} \mathrm{Ni}_{1}$ nanoparticles with slight concave Pt-rich (111) surface exhibited the highest ORR activity. We attributed the enhanced ORR activity of the octahedral $\mathrm{Pt}_{1} \mathrm{Ni}_{1}$ nanoparticles to their unique Ni-rich near-surface structure and ultrathin Pt shells along (111) facets formed after the initial electrochemical activation. This unique surface structure could enable both electronic and surface lattice strain effects to modify the electronic band structure towards a more favourable adsorption and thus the enhanced ORR activity.

\section{EXPERIMENTAL DETAILS}

\section{Chemicals and materials}

Platinum(II) acetylacetonate $\left[\mathrm{Pt}(\mathrm{acac})_{2}\right]$, nickel(II) acety- 
lacetonate $\left[\mathrm{Ni}(\mathrm{acac})_{2}\right]$, DMF $(>99.9 \%)$ and anhydrous ethanol were all obtained from Sigma-Aldrich. Benzoic acid $\left(\mathrm{C}_{6} \mathrm{H}_{5} \mathrm{COOH},>99.5 \%\right)$ and $70 \%$ re-distilled $\mathrm{HClO}_{4}$ were purchased from Alfa Aesar. Nafion (5 wt.\%) and Vulcan XC-72R carbon were obtained from Sigma-Aldrich. All chemicals were used as received without further purification. Water used in all experiments was supplied by a Water Purifier Nanopure water system $(18.3 \mathrm{M} \Omega \mathrm{cm})$.

\section{Synthesis of highly monodisperse, surfactant-free octahedral $\mathrm{Pt}_{x} \mathrm{Ni}_{1-x}$ nanoparticles}

In a typical synthesis, $\mathrm{Pt}(\mathrm{acac})_{2}(8 \mathrm{mg}), \mathrm{Ni}(\mathrm{acac})_{2}$ (from 0 $\mathrm{mg}$ to $15.7 \mathrm{mg}$ ) and benzoic acid (100 $\mathrm{mg})$ were dissolved in $10 \mathrm{~mL} \mathrm{DMF}$, followed by $10 \mathrm{~min}$ sonication. The resulting homogeneous solution was transferred into a $25-\mathrm{mL}$ Teflon-lined stainless-steel autoclave and heated at $200^{\circ} \mathrm{C}$ for $42 \mathrm{~h}$ before it was cooled down to room temperature.

\section{Synthesis of active carbon-supported octahedral $\mathrm{Pt}_{x} \mathrm{Ni}_{1-x}$ nanoparticles $(\mathrm{PtNi} / \mathrm{C})$}

Before washing the as-synthesized octahedral PtNi nanoparticles, the nanoparticles were loaded onto a carbon support (Vulcan XC-72R) through a colloidal deposition process. Firstly, one gram of carbon powder was exposed to $100 \mathrm{~mL}$ of $5 \mathrm{~mol} \mathrm{~L}^{-1} \mathrm{HCl}$ at $50^{\circ} \mathrm{C}$ for $12 \mathrm{~h}$ with continuous stirring. This material was washed with water and ethanol several times to remove excess $\mathrm{HCl}$ and dried at $80^{\circ} \mathrm{C}$ overnight. This treatment makes their dispersion extremely stable in DMF and ethanol (up to several hours). In addition, this treatment introduces surface functional groups, which is responsible for improved adsorption of metal nanoparticles. Secondly, $50 \mathrm{mg}$ of activated carbon was dispersed in $20 \mathrm{~mL}$ of ethanol. The as-synthesized DMF solutions of PtNi nanoparticles and the activated carbon solution were both sonicated separately for $30 \mathrm{~min}$. The nanoparticle solution was then added dropwise to the carbon solution, and they were sonicated together for another $30 \mathrm{~min}$ with gentle shaking and stirred overnight. Finally, the $\mathrm{PtNi} / \mathrm{C}$ was collected by centrifugation, washed three times with ethanol, and dried at $80^{\circ} \mathrm{C}$ for $1 \mathrm{~h}$ under ambient conditions.

\section{Materials characterizations}

The morphology, microstructure and composition of the products were studied by transmission electron microscopy (TEM; JEOL, JEM-2010, 200 kV). High-resolution TEM (HRTEM) and energy-dispersive X-ray spectroscopy (EDX) were both carried out on HRTEM; JEOL, JEM-2100F, $200 \mathrm{kV}$. The samples were prepared by dropping an isopropanol dispersion of samples onto carbon-coated copper TEM grids using pipettes and dried under ambient condition. The compositions of the products were determined by an inductively coupled plasma-atomic emission spectrometer (ICP-AES, X Series 2, Thermo Scientific USA). Powder X-ray diffraction (XRD) patterns were recorded using a Bruker diffractometer with $\mathrm{Cu} \mathrm{Ka}$ radiation (D8 Advance X-ray diffractometer, $\mathrm{Cu} \mathrm{Ka}, \lambda=$ $1.5406 \AA$, $40 \mathrm{kV}$ and $40 \mathrm{~mA}$ ) to study the crystallographic information of the samples. X-ray photoelectron spectroscopy (XPS) measurements were performed by using a VG Thermo ESCALAB 250 spectrometer (VG Scientific) operated at $120 \mathrm{~W}$. The binding energy was calibrated against the carbon 1s line.

\section{Electrochemical measurements}

All the measurements were carried out using an Autolab potentiostat/galvanostat (Model PGSTAT-72637, Brinkman Instruments) with rotation control (Model 636) in a standard three-electrode cell at room temperature. A Pine Instrument Company glassy carbon electrode of 0.196 $\mathrm{cm}^{2}$ geometric area was employed as the working electrode. The catalyst ink was prepared by mixing the catalyst with water, 2-propanol, and Nafion (5 wt.\%) $(v / v / v=4 / 1 / 0.02)$ to form a $2 \mathrm{mg} \mathrm{mL}^{-1}$ suspension under sonication. A calculated amount of catalyst ink was deposited onto the working electrode with a Pt loading of $20 \mu \mathrm{g} \mathrm{cm}^{-2}$ geo. A saturated calomel electrode (SCE) and a Pt plate $(1 \mathrm{~cm} \times 1$ $\mathrm{cm})$ were used as reference and counter electrode, respectively. All potentials in this paper were measured against the SCE reference electrode and converted to the $\mathrm{pH}$-independent reversible hydrogen electrode (RHE) reference scale by $E(v s$. RHE $)=E(v s$. SCE $)+0.245+0.0591 \mathrm{pH}$, and the readout currents were recorded without any $i \mathrm{R}$ drop correction during the measurements. After being dried at room temperature under a gentle flow of nitrogen, the catalyst-coated glassy carbon working electrode was first wetted with nanopure water, attached to the shaft of the electrode rotator, and guided into the electrolyte.

For every measurement, a clean electrochemical cell was filled with fresh $0.1 \mathrm{~mol} \mathrm{~L}^{-1} \mathrm{HClO}_{4}$ electrolyte. The electrolyte was de-oxygenated with a steady stream of ultrahigh pure $\mathrm{N}_{2}$ for $30 \mathrm{~min}$. The working electrode was first electrochemically cleaned via potential cycling between 0.1 and $1.1 \mathrm{~V}$ versus the RHE for 50 cycles at $200 \mathrm{mV} \mathrm{s}^{-1}$ until a stable cyclic voltammogram (CV) was recorded. The minimum potential should be just above the potential for $\mathrm{H}_{2}$ evolution, which will be scan rate and catalyst dependent. To avoid the corrosion of either the support or the catalyst 
itself, the positive limit of $1.1 \mathrm{~V}$ was never exceeded in any experiment [16].

The CV measurements for the electrochemical surface area determination was carried out by cycling between 0.1 and $1.1 \mathrm{~V} v s$. RHE at $20 \mathrm{mV} \mathrm{s}^{-1}$.

For the ORR measurements, the saturation gas was switched to ultra-high purity $\mathrm{O}_{2}$, and the electrolyte was saturated for 30 min with $\mathrm{O}_{2}$. Linear-sweep voltammetry (LSV) measurements were conducted under an oxygen atmosphere by sweeping the potential from $0.1 \mathrm{~V}$ ( $v s$. RHE) anodically to $1.1 \mathrm{~V}$ at a scan rate of $20 \mathrm{mV} \mathrm{s}^{-1}$ and a rotation speed of $1600 \mathrm{rpm}$. The electrocatalytic activity of catalysts was compared by their mass- and area-specific activities using the mass-transport correction for thin-film RDEs [17,18]:

$$
I_{\mathrm{k}}=I_{d} I /\left(I_{\mathrm{d}}-I\right) \text {, }
$$

where $I$ is the experimentally obtained current, $I_{\mathrm{d}}$ refers to the measured diffusion-limited current, and $I_{\mathrm{k}}$ is the masstransport free kinetic current.

The Pt mass-specific activities were estimated via the calculation of $I_{\mathrm{k}}$ and normalization to the Pt-loading of the working electrode. The area-specific activities were estimated via the calculation of $I_{\mathrm{k}}$ and normalization to the electrochemical surface area. All experiments were repeated three times to confirm the reproducibility and to improve the accuracy in the determination of electrochemical activities. The electrocatalytic activities of the catalysts toward ORR were quantified at $E=0.90 \mathrm{~V} v s$. RHE because the interferences from mass-transport losses cannot be completely excluded at higher current densities observed below $0.90 \mathrm{~V}$.

\section{RESULTS AND DISCUSSION}

Highly monodisperse, surfactant-free octahedral $\mathrm{Pt}_{x} \mathrm{Ni}_{1-x}$ nanoparticles with different surface structure and composition were prepared by simultaneous reduction of $\mathrm{Pt}(\mathrm{acac})_{2}$ and $\mathrm{Ni}(\mathrm{acac})_{2}$ using $\mathrm{DMF}$ as both solvent and reducing agent, which contained benzoic acid as the structure-directing agent. In a typical synthesis, $\mathrm{Pt}(\mathrm{acac})_{2}$, $\mathrm{Ni}(\mathrm{acac})_{2}$, and benzoic acid were co-dissolved in $10 \mathrm{~mL}$ DMF. The homogeneous solution was then ultrasonicated for about $10 \mathrm{~min}$ before transferred into a 25 $\mathrm{mL}$ Teflon-lined stainless-steel autoclave and heated at a pre-heated $200^{\circ} \mathrm{C}$ oven for $42 \mathrm{~h}$. The products were collected by centrifugation and washed three times with methanol.

The morphologies and monodispersity of the nanoparticles were initially determined by TEM. Fig. 1a, b shows the representative TEM images of $\mathrm{Pt}_{1} \mathrm{Ni}_{3}$ nanoparticles at different magnifications. It is clearly revealed that highly monodisperse concave octahedral nanoparticles are obtained in high yield. In addition, the aggregation of nanoparticles (indicated by green dashed circles in Fig. 1a) suggests their clean surface of the as-synthesized nanoparticles. From the size distribution histogram shown in Fig. 1b (inset at the top right), the as-prepared octahedral $\mathrm{Pt}_{1} \mathrm{Ni}_{3}$ nanoparticles exhibits an average edge length of $4.3 \pm 0.5 \mathrm{~nm}$ (the edge length measurement is shown in the inset at the bottom right in Fig. 1b). After supported on the activated Vulcan XC-72 carbon, the octahedral $\mathrm{Pt}_{1} \mathrm{Ni}_{3}$ nanoparticles are uniformly distributed on them without significant size and shape change, further indicating the high monodispersity of our synthesized surfactant-free octahedral nanoparticles (Fig. 1c and Fig. S1 in Supplementary information). The single nanoparticle (the corresponding crystal model is shown in the inset at the bottom right in Fig. 1c) indicated by red dashed circle demonstrates that the octahedral nanoparticles are randomly distributed on the carbon support. From the HRTEM images of the individual nanoparticles shown in Fig. 1d, the obvious concave structure is observed, similar to the observation in previous studies $[8,19]$. The appearance of the concaveness indicates the site-specific composition segregation occurs during the synthesis of bimetallic PtNi nanoparticles [8,20]. The atomic ratio of $\mathrm{Pt} / \mathrm{Ni}$ was determined to be $1 / 3$ by EDX and ICP-AES analysis.

Interestingly, we found that the degree of concaveness of the octahedral $\mathrm{Pt}_{x} \mathrm{Ni}_{1-x}$ nanoparticles correlated with the $\mathrm{Ni}$ content in the bulk. Fig. 2 shows the corresponding TEM images of $\mathrm{Pt}_{3} \mathrm{Ni}_{1}$ (Fig. 2a, b) and $\mathrm{Pt}_{1} \mathrm{Ni}_{1}$ (Fig. 2c, d) nanoparticles synthesized with the same condition used in the synthesis of concave $\mathrm{Pt}_{1} \mathrm{Ni}_{3}$ but with different input ratios of $\mathrm{Pt} / \mathrm{Ni}$. From the TEM images, it is clear that increasing the amount of $\mathrm{Ni}(\mathrm{acac})_{2}$ results in an increase in the degree of concaveness of the (111) facets of the octahedral $\mathrm{Pt}_{x} \mathrm{Ni}_{1-x}$ nanoparticles while maintains their octahedral shape and size distribution (insets at the bottom right in Fig. 2a, c). For instance, well-defined octahedral with flat (111) facets were obtained when the initial input ratio of $\mathrm{Pt} / \mathrm{Ni}$ was $3 / 1$. While when the initial $\mathrm{Pt} / \mathrm{Ni}$ input ratio decreased to 1 , some of the $\mathrm{Pt}_{x} \mathrm{Ni}_{1-x}$ began to develop some slight concaveness along their (111) facets. The increase of the degree of concaveness of the nanoparticles with increase of $\mathrm{Ni}$ content indicates that $\mathrm{Ni}$ plays an important role [19]. In addition, we found that the presence of $\mathrm{Ni}$ could also help to maintain their octahedral shape during the synthesis [6]. When $\mathrm{Pt}(\mathrm{acac})_{2}$ was used as the only precursor, a mixture 

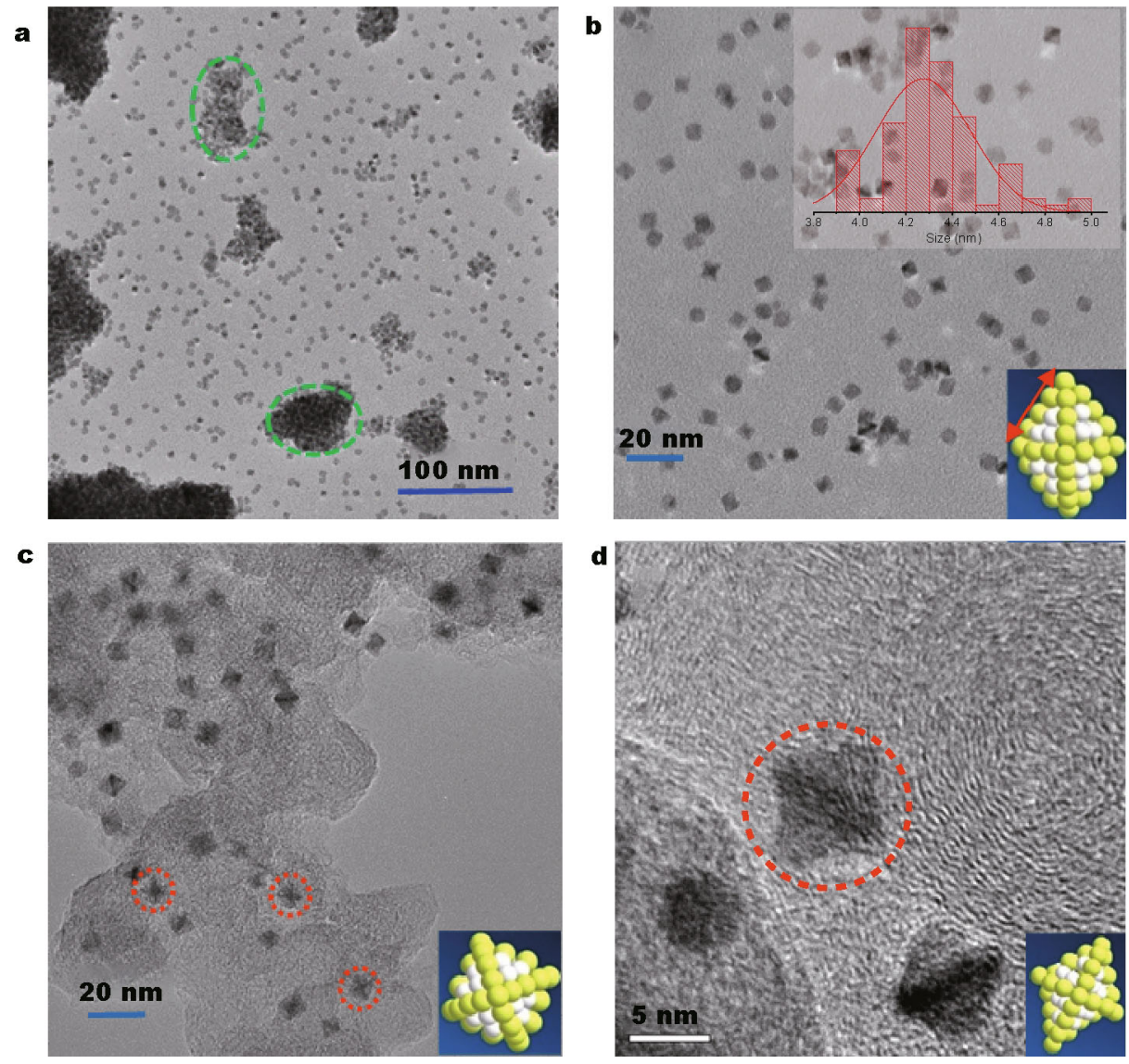

Figure 1 (a, b) Representative TEM images of highly monodisperse, surfactant-free octahedral concave $\mathrm{Pt}_{1} \mathrm{Ni}_{3}$ nanoparticles at different magnifications. The inset at the top right in (b) shows the particle size distribution histogram. (c) TEM and (d) HRTEM images of the activated carbon-supported $\mathrm{Pt}_{1} \mathrm{Ni}_{3}$ nanoparticles, respectively. The insets at the bottom right in (b), (c), and (d) are the corresponding crystal models of the octahedral $\mathrm{Pt}_{x} \mathrm{Ni}_{1-x}$ nanoparticles. Pt atom: green ball; Ni atom: white ball.

of Pt nanocubes and cuboctahedral were obtained (Fig. S2). The morphological changes described here indicate that during the formation of octahedral $\mathrm{Pt}_{x} \mathrm{Ni}_{1-x}$ nanoparticles, Pt nanocubes and/or cubotahedral seeds are formed first, then residual $\mathrm{Ni}$ and $\mathrm{Pt}$ atoms are added to the surface of cubic seeds, and they initially grow via continuous deposition on the (100) facets, leading to the formation of an octahedron enclosed by (111) facets, which is similar to the seed-mediated synthesis of octahedral Pd nanoparticles (Scheme 1) [21]. Nevertheless, the exact mechanisms by which the increase of degree of concaveness of the octahedral $\mathrm{Pt}_{x} \mathrm{Ni}_{1-x}$ nanoparticles with more Ni content in bulk is still unclear and demands more detailed studies.

XRD has proven to be a versatile technique to capture the internal crystal structure and composition changes of nanoparticles. Once supported on activated carbon, we measured the crystal phases of the products by XRD. As shown in Fig. 3 a, the clear diffraction peaks with $2 \theta$ degree centered at $39.8^{\circ}, 46.2^{\circ}, 67.5^{\circ}, 81.2^{\circ}$, and $85.7^{\circ}$ could be indexed to the (111), (200), (220), (311), and (222) planes of the Pt face-centered cubic (fcc) crystal structure. Compared to the standard JCPDS data of Pt (No. 65-2868), the diffraction peaks position for the octahedral $\mathrm{Pt}_{x} \mathrm{Ni}_{1-x}$ nanoparticles shift towards higher $2 \theta$ values reflecting lattice contraction with more $\mathrm{Ni}$ content. Moreover, no $\mathrm{Ni}$ single component peak was observed, indicating the formation of single-phase PtNi alloys. The chemical states and compositions of the as-synthesized octahedral $\mathrm{Pt}_{x} \mathrm{Ni}_{1-x}$ nanoparticles were further investigated by XPS. Taking $\mathrm{Pt}_{1} \mathrm{Ni}_{1} / \mathrm{C}$ as an example, the survey XPS spectrum of the composites (Fig. $3 \mathrm{~b}$ ) clearly indicates the presence of $\mathrm{Pt}$ and Ni. In the Pt XPS spectrum (Fig. 3c), the peaks at 71.7 and $75.1 \mathrm{eV}$ are attributed to the $4 \mathrm{f}_{7 / 2}$ and $4 \mathrm{f}_{5 / 2}$ binding energies of zero-valent state $\mathrm{Pt}$, respectively. And the binding energies at 72.4 and $75.9 \mathrm{eV}$ correspond to the $4 \mathrm{f}_{7 / 2}$ and $4 \mathrm{f}_{5 / 2}$ levels of $\mathrm{Pt}^{2+}$ [22]. For the Ni 2p XPS spectrum (Fig. 3d), 
a

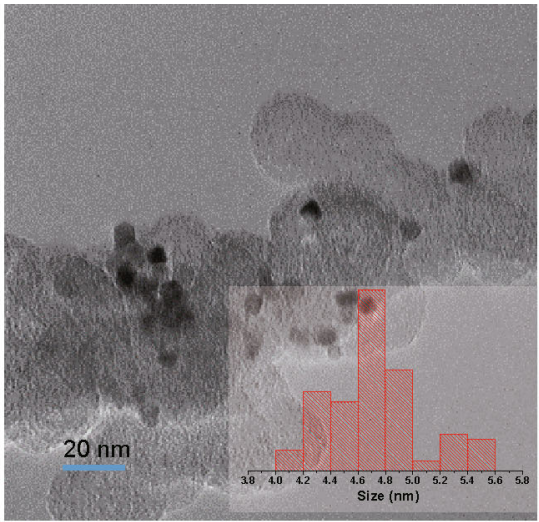

c

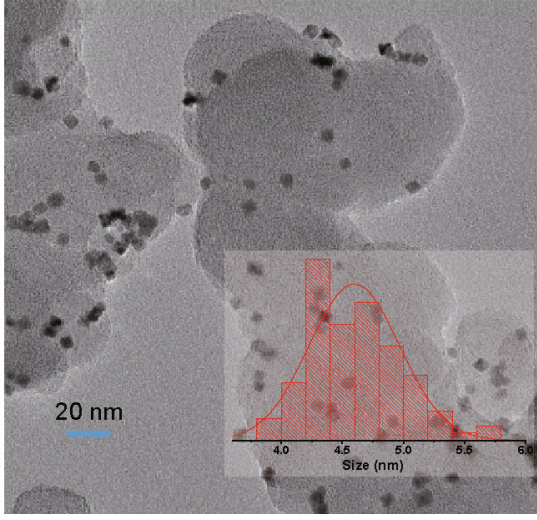

b

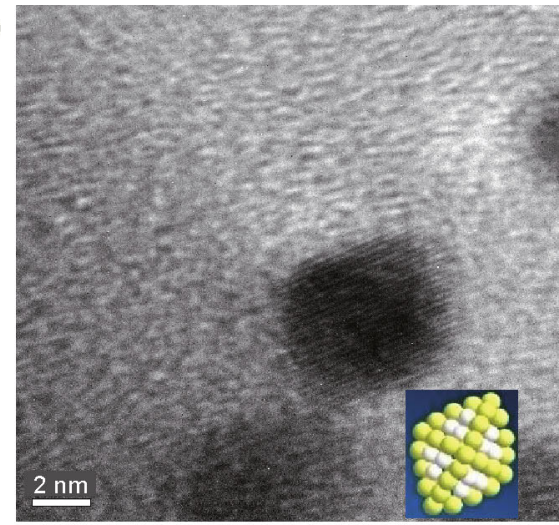

d

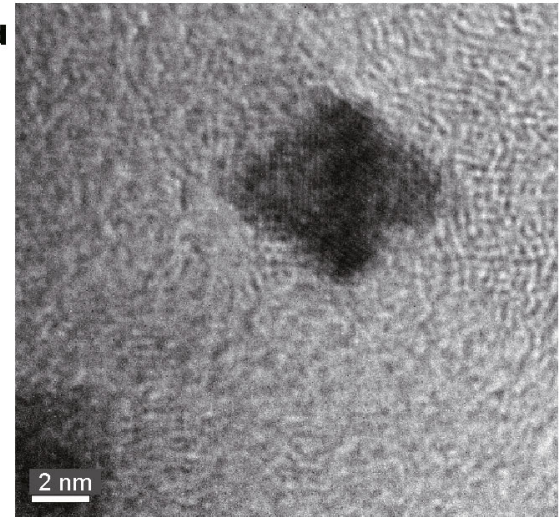

Figure 2 (a, c) TEM and (b, d) HRTEM images of the octahedral $\mathrm{Pt}_{x} \mathrm{Ni}_{1-x}$ nanoparticles synthesized with the same condition used in the synthesis of concave $\mathrm{Pt}_{1} \mathrm{Ni}_{3}$ but with different input ratios of $\mathrm{Pt} / \mathrm{Ni}$. ( $\left.\mathrm{a}, \mathrm{b}\right) \mathrm{Pt} / \mathrm{Ni}=3 / 1 ;(\mathrm{c}, \mathrm{d}) \mathrm{Pt} / \mathrm{Ni}=1 / 1$. The inset at the bottom right in a and $\mathrm{c}$ show the corresponding particles size distribution histogram. The insets at the bottom right in Fig. $1 \mathrm{~b}$ and $\mathrm{d}$ are the corresponding crystal models of the octahedral $\mathrm{Pt}_{x} \mathrm{Ni}_{1-x}$ nanoparticles.
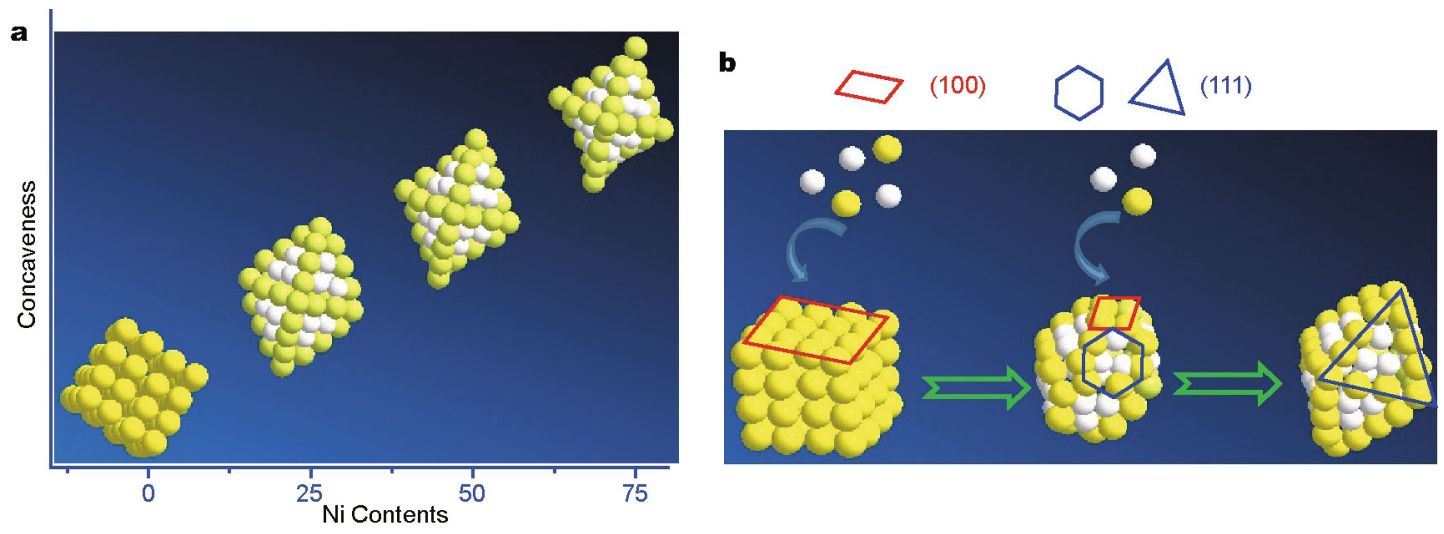

Scheme 1 (a) The degree of concaveness of the octahedral $\mathrm{Pt}_{x} \mathrm{Ni}_{1-x}$ nanoparticles as a function of Ni contents; (b) proposed mechanism illustration for the synthesis of octahedral $\mathrm{Pt}_{x} \mathrm{Ni}_{1-x}$ nanoparticles.

in addition to zero-valent $\mathrm{Ni}$ metal, we could also find $\mathrm{Ni}^{\mathrm{x}+}$ in the composites, mainly due to the inclusion of $\mathrm{Ni}(\mathrm{OH})_{2}$.

To better understand the growth process of the highly monodisperse, surfactant-free octahedral $\mathrm{Pt}_{x} \mathrm{Ni}_{1-x}$ nanoparticles during the synthesis, we studied their shape and size evolution with different reaction times by using
TEM technique. As can be seen from Fig. S3 in SI, the well-defined octahedral nanoparticles in high yield and dispersity was obtained when the reaction time was only $2 \mathrm{~h}$ (Fig. S3a), which indicated the fast formation kinetics of the synthesis strategy. This was different from earlier studies, where only near-spherical cuboctahedra around 

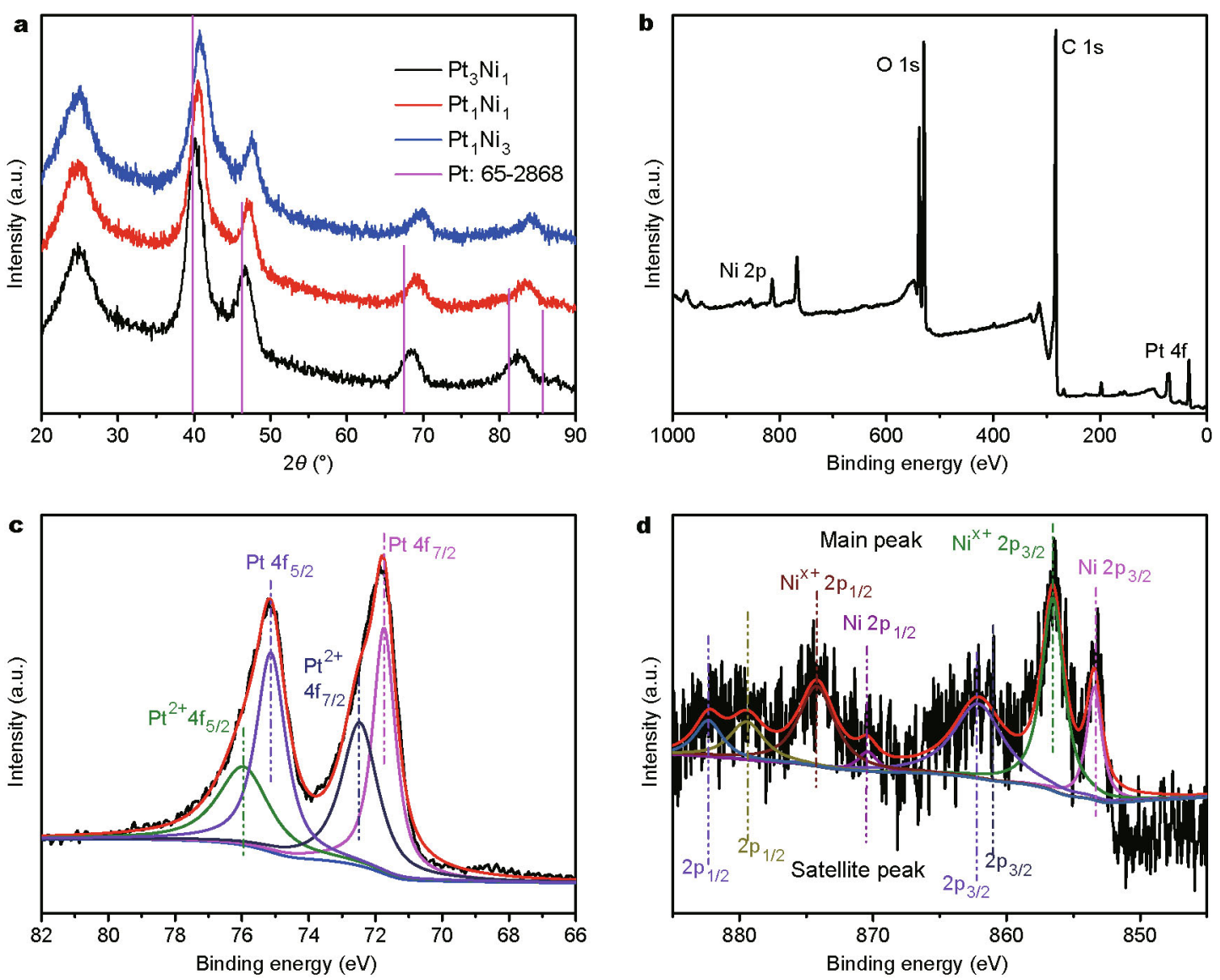

Figure 3 XRD patterns of the activated carbon supported highly monodisperse, surfactant-free octahedral $\mathrm{Pt}_{x} \mathrm{Ni}_{1-x}$ nanoparticles. For comparison, corresponding XRD pattern bulk Pt from the JCPDS was also included. (b-d) XPS spectra of the Pt ${ }_{1} \mathrm{Ni}_{1} / \mathrm{C}$. (b) Survey spectrum; (c) Pt $4 \mathrm{f}$ and (d) Ni 2 p.

2 to $8 \mathrm{~nm}$ in diameter and a branched structure at larger sizes between 6 and $12 \mathrm{~nm}$ were obtained even after a growth period of $4 \mathrm{~h}$ [19]. With reaction time increasing to $6 \mathrm{~h}$ (Fig. S3b) and $12 \mathrm{~h}$ (Fig. S3c), the as-synthesized $\mathrm{Pt}_{x} \mathrm{Ni}_{1-x}$ nanoparticles retained their size and octahedral shape, the only change may be the surface composition [7]. The corresponding digital photographs of the products at different reaction times, shown in Fig. S4, further indicated that the reaction occurred within $2 \mathrm{~h}$.

In order to elucidate the experimental conditions of the formation of highly monodisperse, concave $\mathrm{Pt}_{x} \mathrm{Ni}_{1-x}$ nanoparticles, some control experiments were carried out. At lower reaction temperature, such as $120^{\circ} \mathrm{C}$ (Fig. $\mathrm{S} 5 \mathrm{a}, \mathrm{b}$ ) and even to $160^{\circ} \mathrm{C}$ (Fig. S5c, d), a large number of irregular shaped $\mathrm{Pt}_{x} \mathrm{Ni}_{1-x}$ nanoparticles were produced. Moreover, from the digital photographs of the activated carbon-supported nanoparticles solution at different reaction temperature, which were shown in Fig. S6 in SI, we found that more Ni could be reduced with increasing the temperature and thus the formation of composition-tun- able nanoparticles [23]. In addition to the reaction temperature, the use of benzoic acid was essential to the synthesis of well-defined octahedral $\mathrm{Pt}_{x} \mathrm{Ni}_{1-x}$ nanoparticles. When the reaction was performed in the absence of benzoic acid, irregular shaped and even some small nanoparticles were obtained under the same experimental conditions $[5,24]$. This might originate from the binding of benzoic acid on their (111) facet during the octahedral PtNi nanoparticles synthesis. However, compared to earlier studies [5,24], we found that concave octahedral $\mathrm{Pt}_{x} \mathrm{Ni}_{1-x}$ nanoparticles were obtained instead of octahedral $\mathrm{Pt}_{x} \mathrm{Ni}_{1-x}$ nanoparticles with flat (111) facet, which might originate from the different reaction conditions. In another work established by Huang et al., where they added carbon support during the synthesis to obtain carbon-supported $\mathrm{Pt}_{x} \mathrm{Ni}_{1-x}$ nanoparticles (PtNi/C) composites, they obtained highly monodisperse octahedral $\mathrm{Pt}_{3} \mathrm{Ni}$ nanoparticles supported on carbon. In their studies, the as-synthesized $\mathrm{Pt}_{3} \mathrm{Ni}$ presented octahedral shape with flat (111) facet, while the composition of the $\mathrm{Pt}_{x} \mathrm{Ni}_{1-x}$ nanoparticles could not be effectively tuned by 
changing the initial mole ratios of $\mathrm{Pt} / \mathrm{Ni}$ during the synthesis. This may be attributed to the difficulty in reducing $\mathrm{Ni}$ precursors in their system $\left(160^{\circ} \mathrm{C}\right.$ and under oil bath condition). When we added activated carbon to the solution during the reaction, we obtained some irregular shaped nanoparticles instead (Fig. S7). Based on the above results and discussion, we found that in our present system, the use of high reaction temperature $\left(200^{\circ} \mathrm{C}\right.$ and reaction at a pre-heated oven), use of benzoic acid, and DMF as the solely solvent played crucial role in the synthesis of highly mondisperse, surfactant-free octahedral $\mathrm{Pt}_{x} \mathrm{Ni}_{1-x}$ nanoparticles. Generally, the high temperature could effectively separate the crystal nucleation and the subsequent growth phases, which resulted in monodisperse nanocrystals [25]. The presence of benzoic acid could greatly improve the yield of octahedral nanoparticles with well-defined (111) facets. At the same time, DMF could serve as the solvent to dissolve the metal precursor, the reductant to reduce the metal precursors, and the endogenous $\mathrm{CO}$ and amines served as the reductant/stabilizer to reduce and stable the
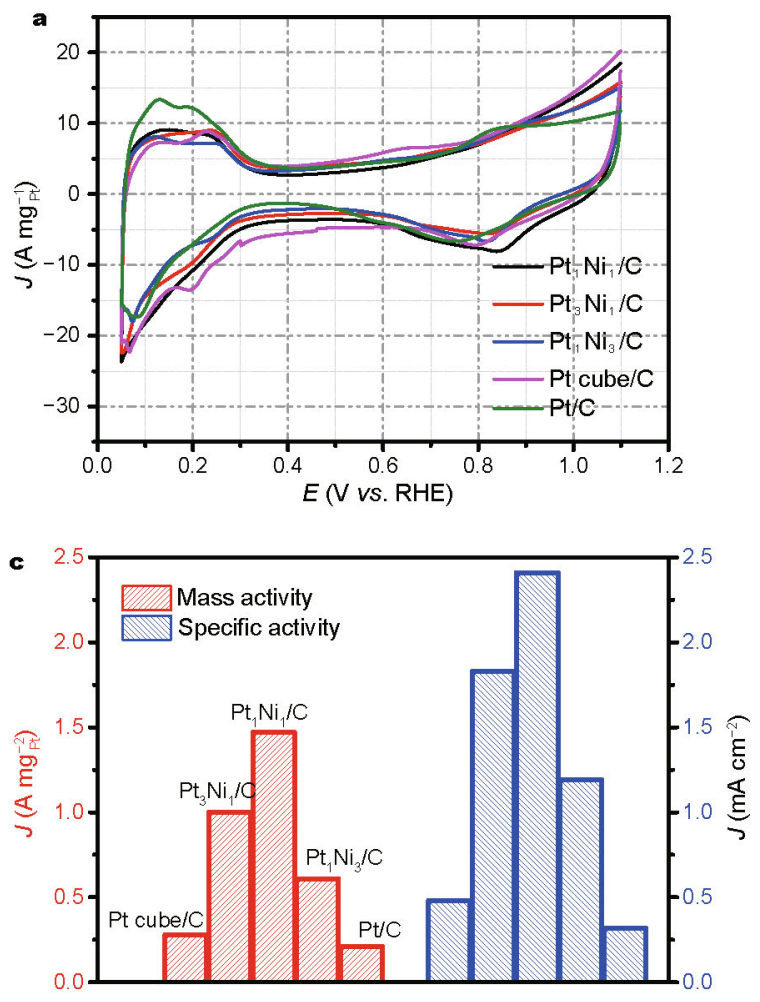

as-synthesized nanoparticles, respectively.

Due to their high monodispersity, surfactant-free surface as well as well-defined active (111) surface, we were able to perform a systematic investigation about the effect of nanoparticle surface structure and composition on ORR activity. CVs of all the $\mathrm{Pt}_{x} \mathrm{Ni}_{1-x} / \mathrm{C}$ in $\mathrm{N}_{2}$-saturated 0.1 mol L-1 $\mathrm{HClO}_{4}$ solution shown in Fig. 4a presented typical Pt characteristics. For comparison, the CV curves of Pt cubes synthesized when only $\mathrm{Pt}(\mathrm{acac})_{2}$ was used as the metal precursors during the synthesis and commercial Pt/C catalysts were also shown in Fig. 4a. It can be seen that the CV profiles of all $\mathrm{Pt}_{x} \mathrm{Ni}_{1-x} / \mathrm{C}$ are similar to the (111) facets $\mathrm{Pt}$ and different from (100) character of Pt cube/C, indicating the dominant (111) facets of them. Interestingly, we found that the position of both surface oxidation and the reduction peaks for all the $\mathrm{Pt}_{x} \mathrm{Ni}_{1-x} / \mathrm{C}$ catalysts and $\mathrm{Pt}$ cube/C exhibited a small yet visible positive shift compared to the $\mathrm{Pt} / \mathrm{C}$ catalyst, with the extent of shift increasing in the order of $\mathrm{Pt}_{1} \mathrm{Ni}_{1} / \mathrm{C}>\mathrm{Pt}_{3} \mathrm{Ni}_{1} / \mathrm{C}>\mathrm{Pt}_{1} \mathrm{Ni}_{3} / \mathrm{C}>\mathrm{Pt}$ cube/C $>\mathrm{Pt} / \mathrm{C}$, indicating reduced adsorption of blocking oxygenated species
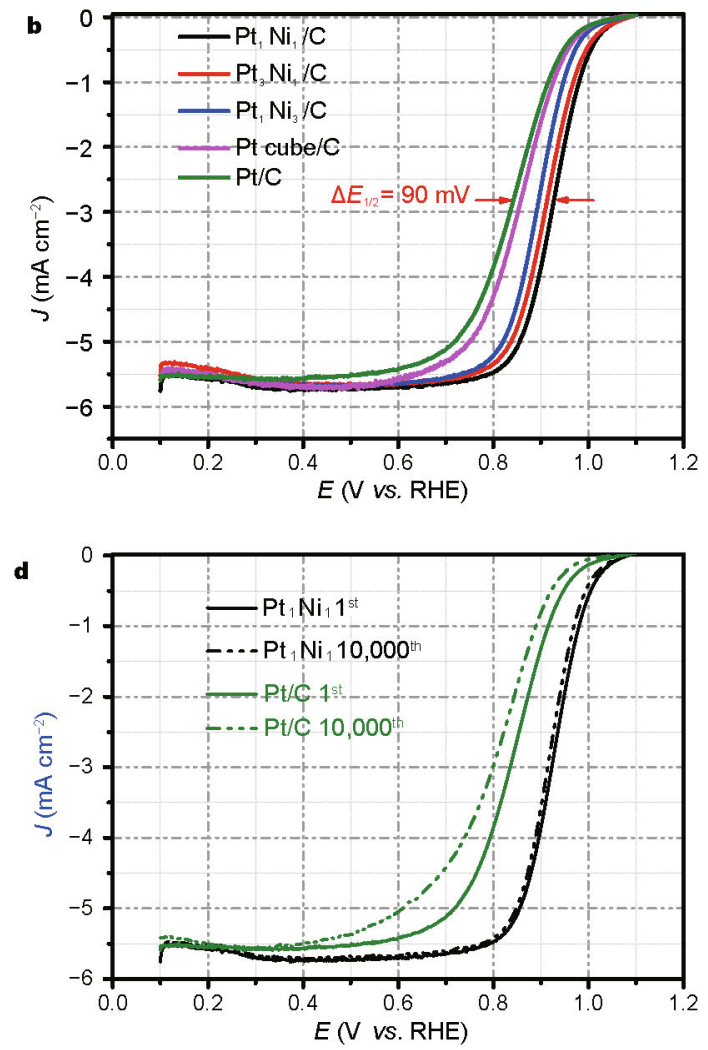

Figure 4 (a) $\mathrm{CV}$ curves of the octahedral $\mathrm{Pt}_{x} \mathrm{Ni}_{1-x} / \mathrm{C}$, Pt cube/C and $\mathrm{Pt} / \mathrm{C}$ catalysts recorded at room temperature in a $\mathrm{N}_{2}$-saturated $0.1 \mathrm{~mol} \mathrm{~L}^{-1} \mathrm{HClO}_{4}$ solution with a scan rate of $20 \mathrm{mV} \mathrm{s}^{-1}$. (b) ORR polarization curves of the octahedral $\mathrm{Pt}_{x} \mathrm{Ni}_{1-x} / \mathrm{C}$, $\mathrm{Pt}$ cube/C and commercial Pt/C catalysts recorded in $\mathrm{O}_{2}$-saturated $0.1 \mathrm{~mol} \mathrm{~L}^{-1} \mathrm{HClO}_{4}$ solution at room temperature with a sweep rate of $20 \mathrm{mV} \mathrm{s}^{-1}$ at $1600 \mathrm{rpm}$. (c) Comparison of Pt mass and specific activities of the octahedral $\mathrm{Pt}_{x} \mathrm{Ni}_{1-x} / \mathrm{C}, \mathrm{Pt}$ cube/C and commercial $\mathrm{Pt} / \mathrm{C}$ catalysts at $0.90 \mathrm{~V}$ vs. $\mathrm{RHE}$. From left to right: $\mathrm{Pt}$ cube/C, $\mathrm{Pt}{ }_{3} \mathrm{Ni}_{1} / \mathrm{C}, \mathrm{Pt}_{1} \mathrm{Ni}_{1} / \mathrm{C}$, $\mathrm{Pt}_{1} \mathrm{Ni}_{3} / \mathrm{C}$ and $\mathrm{Pt} / \mathrm{C}$, respectively. (d) Polarization curves for the ORR on $\mathrm{Pt}_{1} \mathrm{Ni}_{1} / \mathrm{C}$ and $\mathrm{Pt} / \mathrm{C}$ before and after 10,000 potential cycles in $\mathrm{O}_{2}$-saturated 0.1 mol L-1 $\mathrm{HClO}_{4}$ solution at room temperature with a potential sweep rate of $20 \mathrm{mV} \mathrm{s}^{-1}$ and a rotation rate of $1600 \mathrm{rpm}$. 
on those $\mathrm{Pt}_{x} \mathrm{Ni}_{1-x} / \mathrm{C}$ catalysts [1]. The electrochemical active surface area (ECSA) can provide important information regarding the number of available active sites of catalysts toward specific catalytic reaction. Based on hydrogen adsorption/desorption region after double-layer correction from the $\mathrm{CV}$ curves and assuming a value to 0.21 $\mathrm{mC} \mathrm{cm}^{-2}$ for the adsorption of a hydrogen monolayer on Pt surface for Pt-based catalysts [26,27], the ECSAs were determined to be 58,55,61, 51, and $63 \mathrm{~m}^{2} \mathrm{~g}_{\mathrm{Pt}}^{-1}$ for the $\mathrm{Pt}$ cube/C, $\mathrm{Pt}_{3} \mathrm{Ni}_{1} / \mathrm{C}, \mathrm{Pt}_{1} \mathrm{Ni}_{1} / \mathrm{C}, \mathrm{Pt}_{1} \mathrm{Ni}_{3} / \mathrm{C}$, and $\mathrm{Pt} / \mathrm{C}$ catalysts, respectively. The similar ECSA value of $\mathrm{Pt}_{1} \mathrm{Ni}_{1} / \mathrm{C}$ compared with $\mathrm{Pt} / \mathrm{C}$ may arise from their clean surface and similar size with $\mathrm{Pt} / \mathrm{C}$. While the higher ECSA value of $\mathrm{Pt}_{1} \mathrm{Ni}_{1} / \mathrm{C}$ relative to $\mathrm{Pt}_{3} \mathrm{Ni}_{1} / \mathrm{C}$ and $\mathrm{Pt}_{1} \mathrm{Ni}_{3} / \mathrm{C}$ might be attributed to their moderate concaveness and mixed surface composition of Pt and $\mathrm{Ni}$ [8].

The ORR electrocatalytic performance of our octahedral $\mathrm{Pt}_{x} \mathrm{Ni}_{1-x}$ nanoparticles were evaluated using the thin film deposited on a rotating disk electrode in $0.1 \mathrm{~mol} \mathrm{~L}^{-1} \mathrm{HClO}_{4}$ solution. Fig. $4 \mathrm{~b}$ shows the LSVs polarization curves of octahedral $\mathrm{Pt}_{x} \mathrm{Ni}_{1-x} / \mathrm{C}, \mathrm{Pt}$ cube/C and commercial Pt/C catalysts recorded in $\mathrm{O}_{2}$-saturated $0.1 \mathrm{~mol} \mathrm{~L}^{-1} \mathrm{HClO}_{4}$ solution at room temperature with a sweep rate of $20 \mathrm{mV} \mathrm{s}^{-1}$ at $1600 \mathrm{rpm}$. We can see that the current densities of all catalysts at high overpotentials reach its diffusion-limited value, $\sim-5.7 \mathrm{~mA} \mathrm{~cm}^{-2}$ (geometric area), indicating a negligible contribution from $\mathrm{O}_{2}$ diffusion through the Nafion film to the electrode surface $[17,26]$. More importantly, the half-wave potential, $E_{1 / 2}$ (the potential at which the current reaches half its diffusion-limited value) increases in the order of $\mathrm{Pt} / \mathrm{C}<\mathrm{Pt}$ cube $/ \mathrm{C}<\mathrm{Pt}_{1} \mathrm{Ni}_{3} / \mathrm{C}<\mathrm{Pt}_{3} \mathrm{Ni}_{1} / \mathrm{C}<\mathrm{Pt}_{1} \mathrm{Ni}_{1} / \mathrm{C}$, and a significant positive shift of nearly $90 \mathrm{mV}$ is observed for $\mathrm{Pt}_{1} \mathrm{Ni}_{1} / \mathrm{C}$, implying significant increase of the ORR activity. Here, the lower ORR activity of $\mathrm{Pt}$ cube/C may be due to the lower activity of (100) facets in $\mathrm{HClO}_{4}$ solution $[28,29]$. The Pt mass activities of our octahedral $\mathrm{Pt}_{x} \mathrm{Ni}_{1-x} / \mathrm{C}$ were compared with the $\mathrm{Pt}$ cube/C and $\mathrm{Pt} / \mathrm{C}$ in the left panel of Fig. 4c. Note that the ORR activity obtained from the commercial $\mathrm{Pt} / \mathrm{C}$ in this work agrees well with the previously reported data in the literature $[12,30]$. At 0.90 $\mathrm{V}$, the Pt mass activities of the octahedral $\mathrm{Pt}_{x} \mathrm{Ni}_{1-x} / \mathrm{C}$ were calculated to be $1.10,1.47$, and $0.61 \mathrm{Amg}_{\mathrm{Pt}}^{-1}$ for $\mathrm{Pt}_{3} \mathrm{Ni}_{1} / \mathrm{C}$, $\mathrm{Pt}_{1} \mathrm{Ni}_{1} / \mathrm{C}$, and $\mathrm{Pt}_{1} \mathrm{Ni}_{3} / \mathrm{C}$, respectively, which were 5,7 , and 3 -fold higher than that of $\mathrm{Pt} / \mathrm{C}$. The specific activities were then compared by normalizing the mass activities to the ECSAs, which were 5.7, 7.5, and 3.7 times higher than that of $\mathrm{Pt} / \mathrm{C}\left(0.32 \mathrm{~mA} \mathrm{~cm} \mathrm{Pt}^{-2}\right)$ for $\mathrm{Pt}_{3} \mathrm{Ni}_{1} / \mathrm{C}, \mathrm{Pt}_{1} \mathrm{Ni}_{1} / \mathrm{C}$, and $\mathrm{Pt}_{1} \mathrm{Ni}_{3} / \mathrm{C}$, respectively (right panel of Fig. $4 \mathrm{c}$ ). The ORR results from all the catalysts tested in the present work were summarized in Table 1. In addition, we found that a similar enhancement was observed at $0.93 \mathrm{~V}$ (the half-wave potential of $\left.\mathrm{Pt}_{1} \mathrm{Ni}_{1} / \mathrm{C}\right)$. As can be seen from Fig. S13 and Table S1, the Pt mass and specific activities towards oxygen reduction were enhanced by 5.9 and 6.2-fold for $\mathrm{Pt}_{1} \mathrm{Ni}_{1} / \mathrm{C}$, respectively, relative to the commercial $\mathrm{Pt} / \mathrm{C}$ catalyst.

We then examined the stability of our octahedral $\mathrm{Pt}_{x} \mathrm{Ni}_{1-x} / \mathrm{C}$ catalysts by potential cycling between 0.6 and $1.0 \mathrm{~V}$ vs. RHE in $\mathrm{O}_{2}$-saturated $0.1 \mathrm{~mol} \mathrm{~L}^{-1} \mathrm{HClO}_{4}$ solution [31]. Fig. 4d shows the ORR polarization curves of $\mathrm{Pt}_{1} \mathrm{Ni}_{1} / \mathrm{C}$ and commercial $\mathrm{Pt} / \mathrm{C}$ catalysts before and after 10,000 potential cycles with a potential sweep rate of 20 $\mathrm{mV} \mathrm{s}^{-1}$ and a rotation rate of $1600 \mathrm{rpm}$. It can be seen that after 10,000 potential cycles, the commercial $\mathrm{Pt} / \mathrm{C}$ shows a degradation of nearly $40 \mathrm{mV}$ in its half-wave potential. However, only $10 \mathrm{mV}$ negative shift is observed for the $\mathrm{Pt}_{1} \mathrm{Ni}_{1} / \mathrm{C}$ catalyst, indicating the enhanced durability of $\mathrm{Pt}_{1} \mathrm{Ni}_{1} / \mathrm{C}$ catalyst. In addition, after 10,000 potential cycles, the $\mathrm{Pt}$ mass and specific activities of $\mathrm{Pt}_{1} \mathrm{Ni}_{1} / \mathrm{C}$ catalyst are still as high as $1.19 \mathrm{~A} \mathrm{mg}_{\mathrm{Pt}}^{-1}$ and $1.95 \mathrm{~mA} \mathrm{~cm}^{-2}$, respectively, which are 5.7 and 6.1-fold higher than those of the initial value of commercial Pt/C catalysts. Simultaneously, the TEM image after ADTs measurements (Fig. S14) indicates that most of the octahedral $\mathrm{Pt}_{1} \mathrm{Ni}_{1}$ nanoparticles are still well-dispersed on carbon support without significant aggregation and shape change, which further demonstrates their high stability.

Table 1 Electrochemical results of the activated carbon supported octahedral $\mathrm{Pt}_{x} \mathrm{Ni}_{1-x}$ nanoparticles, $\mathrm{Pt}$ cube/C and commercial $\mathrm{Pt} / \mathrm{C}$ catalysts. All activities at $0.90 \mathrm{~V}$ vs. RHE in $\mathrm{O}_{2}$-saturated $0.1 \mathrm{~mol} \mathrm{~L}^{-1} \mathrm{HClO}_{4}$ solution, $1600 \mathrm{rpm}, 20 \mathrm{mV} \mathrm{s}^{-1}$

\begin{tabular}{ccccc}
\hline Sample & ECSA $\left(\mathrm{m}^{2} \mathrm{~g}^{-1}\right)$ & $E_{1 / 2}(\mathrm{~V})$ & Mass activity $\left(\mathrm{A} \mathrm{mg}^{-1} \mathrm{Pt}\right)$ & Specific activity $\left(\mathrm{mA} \mathrm{cm}^{-2} \mathrm{Pt}\right)$ \\
\hline $\mathrm{Pt}_{1} \mathrm{Ni}_{1} / \mathrm{C}$ & 61.0 & 0.93 & 1.47 & 1.10 \\
$\mathrm{Pt}_{3} \mathrm{Ni}_{1} / \mathrm{C}$ & 55.0 & 0.91 & 0.61 & 1.83 \\
$\mathrm{Pt}_{1} \mathrm{Ni}_{3} / \mathrm{C}$ & 51.0 & 0.89 & 0.28 & 0.19 \\
$\mathrm{Pt}-\mathrm{Cube} / \mathrm{C}$ & 58.0 & 0.86 & 0.21 & 0.32 \\
$\mathrm{Pt} / \mathrm{C}$ & 63.0 & 0.84 & & 0.19 \\
\hline
\end{tabular}


Overall, the ORR activity of our $\mathrm{Pt}_{x} \mathrm{Ni}_{1-x} / \mathrm{C}$ catalysts increased in the order of $\mathrm{Pt}_{1} \mathrm{Ni}_{1} / \mathrm{C}>\mathrm{Pt}_{3} \mathrm{Ni}_{1} / \mathrm{C}>\mathrm{Pt}_{1} \mathrm{Ni}_{3} / \mathrm{C}$. Earlier studies have shown that electrochemical activated (after 25 potential cycles) $\mathrm{Pt}_{x} \mathrm{Ni}_{1-x}$ catalysts have changed their bulk composition to roughly $\mathrm{Pt}_{3} \mathrm{Ni}$ and thus the residual bulk Ni will not be an sufficient descriptor for ORR activity $[8,32]$. In our present study, by using the EDX and ICP-AES analysis, we found that the atomic ratio of $\mathrm{Pt} / \mathrm{Ni}$ after the initial potential cycling between 0.1 and $1.1 \mathrm{~V}$ versus the RHE for 50 cycles at $200 \mathrm{mV} \mathrm{s}^{-1}$ (in the section of electrochemical measurement) indeed changed to $\mathrm{Pt}_{3} \mathrm{Ni}_{1}$ regardless of their initial bulk composition. Moreover, due to the similar size distribution of these three octahedral catalysts, the difference in their ORR activities could be attributed to their surface structure (the degree of concaveness) and composition. The inferior ORR activity of $\mathrm{Pt}_{3} \mathrm{Ni}_{1} / \mathrm{C}$ may be caused by their thick Pt overlayer after potential cycles. On the other hand, due to the largest degree of concaveness, after the potential cycles, the $\mathrm{Pt}_{1} \mathrm{Ni}_{3} / \mathrm{C}$ losts most of its active (111) facets and thus results in low activity. While for the $\mathrm{Pt}_{1} \mathrm{Ni}_{1} / \mathrm{C}$ catalysts, very thin $\mathrm{Pt}$ shell and Ni-rich sub-surface layer formed after the potential cycles facilitate the optimal electronic and geometric effects toward the ORR.

\section{CONCLUSIONS}

In summary, we have developed a generalized strategy to synthesize highly monodisperse, surfactant-free octahedral $\mathrm{Pt}_{x} \mathrm{Ni}_{1-x}$ nanoparticles with different surface structure and composition. With increasing the $\mathrm{Ni}$ content in the bulk composition, we found that the degree of concaveness of (111) facet of the octahedral $\mathrm{Pt}_{x} \mathrm{Ni}_{1-x}$ nanoparticles increased significantly. Due to their similar size and nearly the same composition after potential scan, we were able to systematically study the effect of surface structure and composition on ORR activity. At $0.90 \mathrm{~V} v s$. RHE, all the octahedral $\mathrm{Pt}_{x} \mathrm{Ni}_{1-x}$ nanoparticles supported on activated carbon exhibited enhanced ORR activity. For instance, the $\mathrm{Pt}$ mass and specific activities of the $\mathrm{Pt}_{1} \mathrm{Ni}_{1} / \mathrm{C}$ catalyst reached $1.47 \mathrm{~A} \mathrm{mg}_{\mathrm{Pt}}^{-1}$ and $2.41 \mathrm{~mA} \mathrm{~cm}^{-2}$, respectively, which were 7 and 7.53-fold higher than those of the state-of-the-art commercial Pt/C catalysts. In addition, the $\mathrm{Pt}_{1} \mathrm{Ni}_{1} / \mathrm{C}$ catalyst also showed improved durability relative to $\mathrm{Pt} / \mathrm{C}$. After 10,000 potential scans between 0.6 and 1.0 $\mathrm{V}$, only $10 \mathrm{mV}$ negative shift in their half-wave potential and still high mass and specific ORR activity (1.19 $\mathrm{A} \mathrm{mg}^{-1} \mathrm{Pt}$ for mass activity and $1.95 \mathrm{~mA} \mathrm{~cm}^{-2}$ for specific activity) were observed for the $\mathrm{Pt}_{1} \mathrm{Ni}_{1} / \mathrm{C}$ catalyst. The present study not only provides a general method to synthesize highly monodisperse, surfactant-free as well as highly active and durable octahedral $\mathrm{Pt}_{x} \mathrm{Ni}_{1-x}$ nanoparticles, but also helps us to well understand the correlation between the structure and activity, which paves the way to rational design and synthesis of highly active catalysts for practical applications in the future.

Received 13 March 2017; accepted 31 March 2017; published online 28 April 2017

1 Stamenkovic VR, Fowler B, Mun BS, et al. Improved oxygen reduction activity on $\mathrm{Pt}_{3} \mathrm{Ni}(111)$ via increased surface site availability. Science, 2007, 315: 493-497

2 Huang X, Zhao Z, Cao L, et al. High-performance transition metaldoped $\mathrm{Pt}_{3} \mathrm{Ni}$ octahedra for oxygen reduction reaction. Science, 2015, 348: 1230-1234

3 Choi SI, Xie S, Shao M, et al. Synthesis and characterization of 9 $\mathrm{nm} \mathrm{Pt}-\mathrm{Ni}$ octahedra with a record high activity of $3.3 \mathrm{~A} / \mathrm{mg}_{\mathrm{Pt}}$ for the oxygen reduction reaction. Nano Lett, 2013, 13: 3420-3425

4 Zhang J, Yang H, Fang J, et al. Synthesis and oxygen reduction activity of shape-controlled $\mathrm{Pt}_{3} \mathrm{Ni}$ nanopolyhedra. Nano Lett, 2010, 10: $638-644$

5 Huang X, Zhao Z, Chen Y, et al. A rational design of carbon-supported dispersive Pt-based octahedra as efficient oxygen reduction reaction catalysts. Energ Environ Sci, 2014, 7: 2957-2962

6 Carpenter MK, Moylan TE, Kukreja RS, et al. Solvothermal synthesis of platinum alloy nanoparticles for oxygen reduction electrocatalysis. J Am Chem Soc, 2012, 134: 8535-8542

7 Cui C, Gan L, Li HH, et al. Octahedral PtNi nanoparticle catalysts: exceptional oxygen reduction activity by tuning the alloy particle surface composition. Nano Lett, 2012, 12: 5885-5889

8 Cui C, Gan L, Heggen M, et al. Compositional segregation in shaped Pt alloy nanoparticles and their structural behaviour during electrocatalysis. Nat Mater, 2013, 12: 765-771

9 Kodama K, Jinnouchi R, Takahashi N, et al. Activities and stabilities of Au-modified stepped-Pt single-crystal electrodes as model cathode catalysts in polymer electrolyte fuel cells. J Am Chem Soc, 2016, 138: 4194-4200

10 Jinnouchi R, Toyoda E, Hatanaka T, et al. First principles calculations on site-dependent dissolution potentials of supported and unsupported pt particles. J Phys Chem C, 2010, 114: 17557-17568

11 Tian N, Zhou ZY, Sun SG, et al. Synthesis of tetrahexahedral platinum nanocrystals with high-index facets and high electro-oxidation activity. Science, 2007, 316: 732-735

12 Wang D, Xin HL, Hovden R, et al. Structurally ordered intermetallic platinum-cobalt core-shell nanoparticles with enhanced activity and stability as oxygen reduction electrocatalysts. Nat Mater, 2012, 12: 81-87

13 Xia BY, Wu HB, Wang X, et al. One-pot synthesis of cubic $\mathrm{PtCu}_{3}$ nanocages with enhanced electrocatalytic activity for the methanol oxidation reaction. J Am Chem Soc, 2012, 134: 13934-13937

14 Xia BY, Wu HB, Li N, et al. One-pot synthesis of Pt-Co alloy nanowire assemblies with tunable composition and enhanced electrocatalytic properties. Angew Chem Int Ed, 2015, 54: 3797-3801

15 Stamenkovic VR, Mun BS, Arenz M, et al. Trends in electrocatalysis on extended and nanoscale Pt-bimetallic alloy surfaces. Nat Mater, 2007, 6: 241-247

16 van der Vliet DF, Wang C, Tripkovic D, et al. Mesostructured thin films as electrocatalysts with tunable composition and surface morphology. Nat Mater, 2012, 11: 1051-1058

17 Gasteiger HA, Kocha SS, Sompalli B, et al. Activity benchmarks 
and requirements for $\mathrm{Pt}$, Pt-alloy, and non-Pt oxygen reduction catalysts for PEMFCs. Appl Catal B-Environ, 2005, 56: 9-35

18 Lu Y, Jiang Y, Gao X, et al. Strongly coupled Pd nanotetrahedron/tungsten oxide nanosheet hybrids with enhanced catalytic activity and stability as oxygen reduction electrocatalysts. J Am Chem Soc, 2014, 136: 11687-11697

19 Gan L, Cui C, Heggen M, et al. Element-specific anisotropic growth of shaped platinum alloy nanocrystals. Science, 2014, 346: $1502-1506$

20 Gan L, Heggen M, Cui C, et al. Thermal facet healing of concave octahedral Pt-Ni nanoparticles imaged in situ at the atomic scale: implications for the rational synthesis of durable high-performance ORR electrocatalysts. ACS Catal, 2016, 6: 692-695

21 Jin $\mathrm{M}$, Zhang $\mathrm{H}$, Xie Z, et al. Palladium nanocrystals enclosed by $\{100\}$ and $\{111\}$ facets in controlled proportions and their catalytic activities for formic acid oxidation. Energ Environ Sci, 2012, 5 : 6352-6357

22 Chen C, Kang Y, Huo Z, et al. Highly crystalline multimetallic nanoframes with three-dimensional electrocatalytic surfaces. Science, 2014, 343: 1339-1343

23 AránAis RM, Dionigi F, Merzdorf T, et al. Elemental anisotropic growth and atomic-scale structure of shape-controlled octahedral Pt-Ni-Co alloy nanocatalysts. Nano Lett, 2015, 15: 7473-7480

24 Wu Y, Cai S, Wang D, et al. Syntheses of water-soluble octahedral, truncated octahedral, and cubic Pt-Ni nanocrystals and their structure-activity study in model hydrogenation reactions. J Am Chem Soc, 2012, 134: 8975-8981

25 Snyder J, McCue I, Livi K, et al. Structure/processing/properties relationships in nanoporous nanoparticles as applied to catalysis of the cathodic oxygen reduction reaction. J Am Chem Soc, 2012 134: 8633-8645

26 Garsany Y, Baturina OA, Swider-Lyons KE, et al. Experimental methods for quantifying the activity of platinum electrocata- lysts for the oxygen reduction reaction. Anal Chem, 2010, 82: 6321-6328

27 Lu Y, Jiang Y, Chen W. PtPd porous nanorods with enhanced electrocatalytic activity and durability for oxygen reduction reaction. Nano Energ, 2013, 2: 836-844

28 Shao M, Chang Q, Dodelet JP, et al. Recent advances in electrocatalysts for oxygen reduction reaction. Chem Rev, 2016, 116 3594-3657

29 Marković NM, Schmidt TJ, Stamenković V, et al. Oxygen reduction reaction on Pt and Pt bimetallic surfaces: a selective review. Fuel Cells, 2001, 1: 105-116

30 Guo S, Zhang S, Sun S. Tuning nanoparticle catalysis for the oxygen reduction reaction. Angew Chem Int Ed, 2013, 52: 8526-8544

31 Sun S, Zhang G, Geng D, et al. A highly durable platinum nanocatalyst for proton exchange membrane fuel cells: multiarmed starlike nanowire single crystal. Angew Chem Int Ed, 2011, 50: 422-426

32 Wang C, Chi M, Wang G, et al. Correlation between surface chemistry and electrocatalytic properties of monodisperse $\mathrm{Pt}_{x} \mathrm{Ni}_{1-x}$ nanoparticles. Adv Funct Mater, 2011, 21: 147-152

Acknowledgments This research was supported by the National Research Foundation, Prime Minister's Office, Singapore under its CREATE Programme. We also acknowledge financial support by the Defence Acquisition Program Administration and Agency for Defence Development (UD120080GD), Republic of Korea.

Author contributions The manuscript was written through contributions of all authors. All authors have given approval to the final version of the manuscript.

Conflict of interest The authors declare that they have no conflict of interest.

Supplementary information Supplementary data are available in the online version of the paper. 


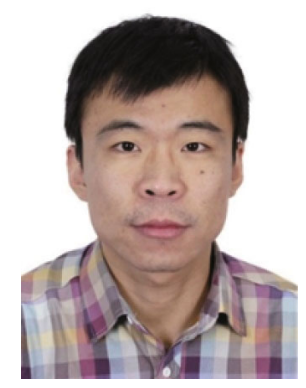

Yizhong Lu received his PhD from Changchun Institute of Applied Chemistry in 2015. He then joined Prof. Xin Wang's group as a research fellow at Nanyang Technological University \& Cambridge Center for Advanced Research in Energy Efficiency in Singapore. Currently, he is a professor in the School of Material Science and Engineering, University of Jinan, Shandong. His research interests focus on the design and synthesis of electrocatalysts for fuel cells.

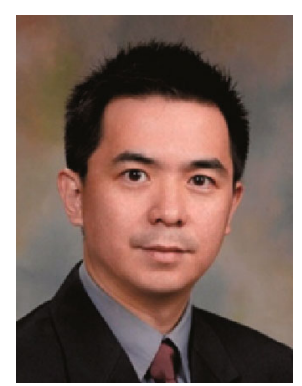

Xin Wang received his PhD degree in chemical engineering from Hong Kong University of Science and Technology in 2002. He joined Nanyang Technological University as an assistant professor in 2005 and was promoted to associate professor with tenure in 2010 and full professor in 2016. His research is focused on electrocatalysis and electrochemical technology for energy harvesting. He is currently a Fellow of Royal Society of Chemistry (FRSC).

\section{具有可控表面结构和组成的 $\mathrm{PtNi}$ 八面体纳米粒子的氧还原活性研究}

逯一中 ${ }^{1,2}$, Larissa Thia ${ }^{1}$, Adrian Fisher ${ }^{3}$, Chi-Young Jung ${ }^{4}$, Sung Chul Yi ${ }^{5^{*}}$, 王昕 ${ }^{1^{*}}$

摘要 双金属催化材料的催化性质可以通过在原子水平下控制材料的表面结构和组成进行有效调节. 本文发展了一种普适性的方法合成

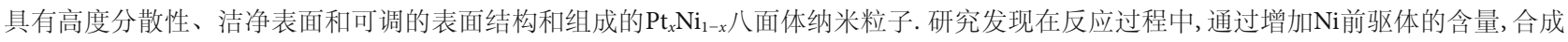
的 $\mathrm{Pt}_{x} \mathrm{Ni}_{1-x}$ 八面体纳米粒子的(111)晶面的凹陷程度逐渐加大. 我们系统研究了 $\mathrm{Pt}_{x} \mathrm{Ni}_{1-x}$ 八面体纳米粒子的表面结构或组成与其氧还原电催化 活性之间的相互关系. 电化学研究结果表明所有的 $\mathrm{Pt}_{x} \mathrm{Ni}_{1-x}$ 八面体纳米粒子均表现出比标准商业 $\mathrm{Pt} / \mathrm{C}$ 催化剂更高的氧还原活性. 更重要的 是, 我们发现 $\mathrm{Pt}_{x} \mathrm{Ni}_{1-x}$ 八面体纳米粒子的表面结构和组成对其氧还原电催化活性具有很大的影响. 研究发现, 具有轻微(111) 晶面凹陷程度的 $\mathrm{Pt}_{1} \mathrm{Ni}_{1}$ 八面体纳米粒子显示出最高的氧还原电催化活性. 在 $0.9 \mathrm{~V}$ (相对于标准氢电极)电势条件下, $\mathrm{Pt}_{1} \mathrm{Ni}_{1}$ 八面体纳米粒子的氧还原质量活性 和面积活性分别为标准商业 $\mathrm{Pt} / \mathrm{C}$ 催化剂的7.0和7.5倍. 该研究不仅提供了一种普适性的方法合成具有高度分散性、洁净表面和可调的表面 结构和组成的 $\mathrm{Pt}_{x} \mathrm{Ni}_{1-x}$ 八面体纳米粒子, 同时可为理解催化材料的结构-性质相互关系规律提供指导. 